\title{
Back to basics: an innovative airway management training programme to support Critical Emergency Medicine nurses
}

\author{
lleana Lulic', Saqr AlHemeiri', AlAnood Bin Sulaiman1, Afaf Sayed Jaafer1, Mirna Diab1, Mahmoud \\ Mustafa², Dinka Lulic ${ }^{3}$
}

${ }^{1}$ Training and Development Center, Ministry of Health and Prevention, Sharjah, United Arab Emirates

2Sudan Resuscitation Council, Khartoum, Sudan

${ }^{3}$ Department of Emergency Medicine, Clinical Hospital Center Zagreb, Zagreb, Croatia

E-mail address: ileanalulic@gmail.com

\section{Purpose of the study}

Immediate access to expert vital function support is a cornerstone of Critical Emergency Medicine (CREM) specialty. CREM concept of multidisciplinary team approach in the management of high acuity airway emergencies brought nurses on the verge of the dawn of a new golden era. It is essential for CREM nurses to possess all available competences for immediate airway function support. Correspondingly, United Arab Emirates (UAE) Ministry of Health and Prevention (MOHAP) highlighted nurse's role in CREM environment as pivotal, which lead to implementation of innovative airway management training programme (ABC CREM), principally focusing on airway skills hands - on training, together with non - technical skills (NTS) teaching.

The aim of our study was to identify the ABC CREM programme growth in UAE since inaugural course held at the MOHAP Training and Development Center (TDC) Sharjah, in November 2018.

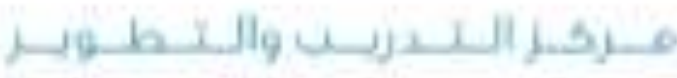
Training and Development Center

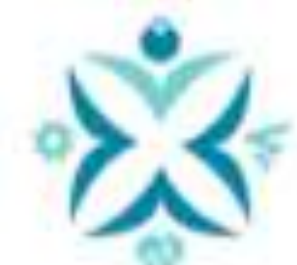

\section{Materials and Methods}

On the 05th of May 2019 MOHAP TDC database search was performed.

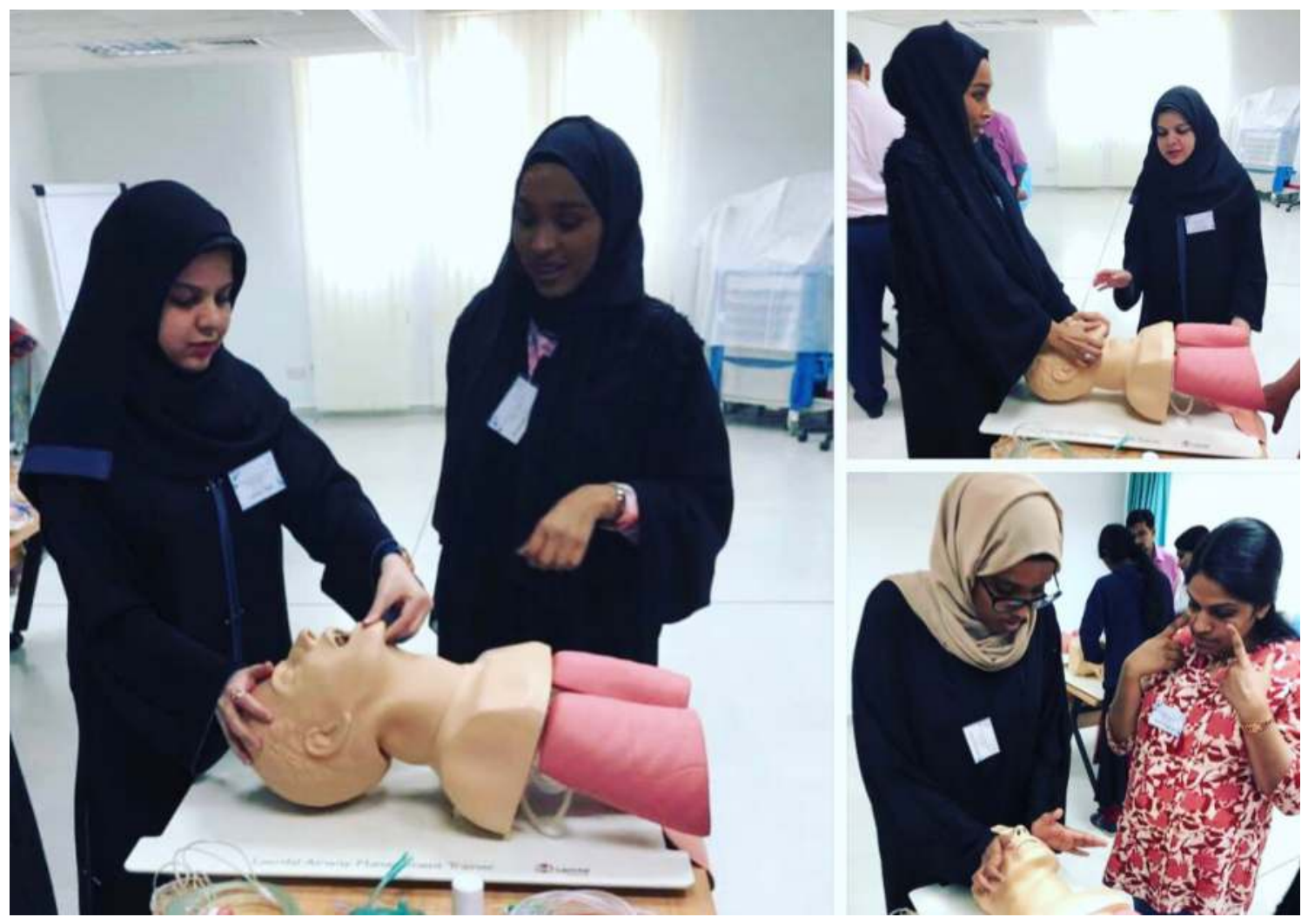

\section{Results}

Up to date, 15 ABC CREM programmes were successfully completed in UAE. A total of 145 (56\%) female nurses, aged from 25 to 58 years (median 38), underwent airway skills hands - on training and NTS teaching. The majority of candidates were from Emergency Department (52\%), followed by nurses working in Intensive Care Units (48\%).

\section{Conclusion}

Our results exhibit positive growth of the CREM based airway management training programme in UAE, spotlighting CREM nurses as a natural extension of the traditional physicians' role during airway emergencies. We strongly encourage embodiment of CREM based airway management training programmes more visibly into nurse's curriculum to secure early successful vital function expertise access. 